\title{
P314: Human Immunodeficiency Virus (HIV) and Hepatitis B Virus (HBV) infection prevention following occupational exposure among staff at regional referral hospital in W. Kenya
}

\author{
BK Burmen ${ }^{1 *}$, DK Bii ${ }^{1}$, J Obunga ${ }^{1}$, P Olilo ${ }^{2}$ \\ From 2nd International Conference on Prevention and Infection Control (ICPIC 2013) \\ Geneva, Switzerland. 25-28 June 2013
}

\section{Introduction}

Post exposure prophylaxis (PEP) with antiretroviral therapy (ART) aids in preventing HIV infection from accidental or occupational exposure. Hospital staff should be vaccinated against $\mathrm{HBV}$ to protect them in the event of accidental exposure to blood and body fluids.

\section{Objectives}

To ascertain adherence and completion of PEP among staff at a regional referral hospital in W. Kenya.

\section{Methods}

We reviewed staff PEP registers at a Regional Referral hospital in Western Kenya between January 2011 and December 2012. National PEP guidelines recommend ART initiation within 72 hours of exposure, use of ART for 28 days post-exposure and HIV re-testing at 1.5, 3 and 6 months following ART initiation. A high-risk exposure occurs when a source is HIV-positive with injury on a mucosal membrane by needleprick, cut or splash. The risk of HBV infection increases if the exposed is not HBVvaccinated and source of exposure is $\mathrm{HBV}$-positive. Chi Square statistics were used to determine factors associated with PEP completion.

\section{Results}

Of 52 hospital staff who initiated PEP; 33 were health workers (63\%), 3 support staff (6\%), 14 students $(27 \%)$, and 2 unknown cadres (4\%). Half were female $(n=27)$;

${ }^{1} \mathrm{HIV}$ and TB Implementation Science and Services, Kenya Medical Research Institute/Centers for Disease Control Research and Public Health

Collaboration, Kisumu, Kenya

Full list of author information is available at the end of the article
29 from in-patient units (56\%) and 30 had high-risk exposures (58\%). Of the staff with documented timing of both HIV exposure and ART initiation $(n=47)$, ART was initiated within the recommended time. Half of all staff $(n=27)$ completed PEP. Reasons for non-completion were side effects $(n=2)$, referral $(n=1)$ and unknown $(n=23)$. PEP completion did not vary by gender $(\mathrm{p}=0.78)$, exposure-type $(p=1.0)$ or exposure-unit $(p=0.75)$. At $1.5,3$, and 6 months after ART initiation, HIV re-testing rates were $96 \%, 25 \%, 17 \%$ and negativity rates were $100 \%$, $100 \%, 75 \%$, respectively. Only $17 \%(n=9)$ of staff were HBV-vaccinated; $94 \%(n=49)$ of sources had unknown HBV status. No intervention was documented HBV prevention.

\section{Conclusion}

Despite timely PEP initiation, low rates of completion negate its intended benefits. Universal precautionpractices and PEP completion should be enforced; so should HBV staff-vaccination and testing for both staff and sources of exposure to tackle the low rates of HBV testing and vaccination.

\section{Disclosure of interest \\ None declared.}

\section{Author details \\ ${ }^{1}$ HIV and TB Implementation Science and Services, Kenya Medical Research Institute/Centers for Disease Control Research and Public Health Collaboration, Kisumu, Kenya. ${ }^{2}$ Clinical, jaramogi oginga odinga teaching and referral hospital, Kisumu, Kenya.}


doi:10.1186/2047-2994-2-S1-P314

Cite this article as: Burmen et al:: P314: Human Immunodeficiency Virus (HIV) and Hepatitis B Virus (HBV) infection prevention following

occupational exposure among staff at regional referral hospital in W.

Kenya. Antimicrobial Resistance and Infection Control 2013 2(Suppl 1):P314.

Submit your next manuscript to BioMed Central and take full advantage of:

- Convenient online submission

- Thorough peer review

- No space constraints or color figure charges

- Immediate publication on acceptance

- Inclusion in PubMed, CAS, Scopus and Google Scholar

- Research which is freely available for redistribution

Submit your manuscript at www.biomedcentral.com/submit

() Biomed Central 